\title{
Sexual Harassment in Transit Environments among College Students in the \#MeToo Era: Reporting Evidence from Six Continents
}

\author{
Vania Ceccato $^{1}$ (D) - Anastasia Loukaitou-Sideris ${ }^{2}$ \\ Accepted: 21 October 2020/ \\ Published online: 12 December 2020 \\ (C) The Author(s) 2020
}

\begin{abstract}
Evaluating patterns of sexual violence against young people across the world in the era of the \#MeToo movement presents great opportunities for research and practice but also challenges. The aim of this article is to critically assess an internet-based methodology employed in a comparative study conducted with university students in 18 different cities, in six continents. While our main purpose is to examine the methodological aspects of this study, the article also presents briefly its major findings and discusses compiled recommendations to curb sexual violence in some of the most important transit systems in the world. Findings show that sexual violence in transit environments is a common occurrence globally, is highly underreported, and ranges considerably from one city to the other, and between gender groups. Lessons from this study suggest that it is crucial to use identical research tools and choose partners who can ensure that research tasks are undertaken on time, ethically, and with good care for the quality of data and the research process. To curb sexual violence on transit, actions tailored to local contexts are necessary, but as underreporting of harassment is prevalent in all contexts, one global need is initiatives that facilitate incident reporting.
\end{abstract}

Keywords Groping · Stalking · Public transportation · University students · Gender · LGBTQI

Special Issue: Research on Sexual Violence in the \#metoo Era: Prevention and Innovative Methodologies Guest Editor: Dr. Leah E. Daigle, Professor, Georgia State University, Department of Criminal Justice and Criminology, Faculty Affiliate in Center for Interpersonal Violence

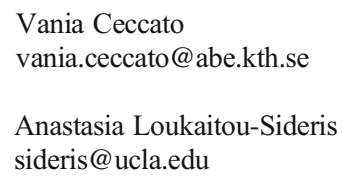

Extended author information available on the last page of the article 


\section{Introduction}

Back in early 2016, a survey was carried out by university students intended to ask Metro passengers about sexual violence in a Scandinavian capital. Unfortunately, the survey received limited response because of two problems: the students administering the survey felt uncomfortable asking questions about sexual victimization, and most people receiving the survey possibly also felt uncomfortable, as they refused to answer it. The emergence of the \#MeToo movement just one year later, which spread rapidly across the internet and cyberspace, made it easier to get information about these problematic everyday life experiences that affect many women. We decided to administer the survey again in 2017, focusing only on university students. This time things went much better, and the survey received more than 1500 responses. Encouraged by this success and wishing to better understand the phenomenon of sexual violence in transit among university students globally, we expanded the survey's scope and content and administered it to university students in 18 countries, in six different continents, ultimately receiving responses from 13,323 students. We found that investigating sexual violence in an international, comparative context presents challenges but also a great set of opportunities.

The aim of this article is to critically assess an internet-based methodology employed in a comparative study conducted with university students in a variety of city and country contexts. The article also illustrates a few examples from the results obtained in 18 different cities, in six continents. We start with a brief overview of the current literature on transit crime and sexual violence. Then we discuss the challenges faced in conducting this research related to ethical, cultural and definitional aspects, as well as some barriers of language and communication encountered by researchers. Finally, in a more practical take, we discuss the commonalities and differences of the compiled recommendations to curb sexual violence in different transit systems around the world, and critically assess the challenges of putting them into practice in different contexts.

Following Breiding et al. (2014), we use the umbrella-term "sexual violence" in this study to cover a variety of sexual behaviors. These include (1) nonverbal sexual violence/abuse, such as stalking, exhibitionism, showing sexually explicit pictures, or making sexual gestures; (2) verbal sexual violence/abuse, such as sexual comments, jeering or taunting, and asking questions about sexual activity, and finally (3) physical sexual violence/abuse, which may involve behaviors such as touching, kissing, and rape. The study sought to provide a comprehensive assessment of trends of sexual violence in 18 cities using an identical 45 -question survey to examine the nature, type, settings, and extent of victimization in public transport settings, and how it differs by gender, sexual orientation, and geographic context among college students in the different city/country contexts. The study was novel in several ways. First, it helped us better understand the challenges and potentials of doing collaborative work using an identical survey instrument distributed primarily through digital means of communication. Second, most studies examining sexual victimization of college students focus on college campuses. Our study, however, examines and briefly illustrates here examples of how students may be victimized by sexual violence during their transit travel to/from campus and to other destinations. Third, the great majority of studies on sexual victimization focus on physical harassment; little work has examined non-contact forms of sexual victimization (Pinchevsky, Magnuson, Augustyn, \& Rennison, 
2019), which however represent the multitude of incidents in transit environments. Fourth, the study's comparative framework allows the examination of sexual victimization in multiple geographic contexts, including countries from Asia, Europe, Africa, Australia, North and South America, drawing from the experiences of cities both in the Global North and the Global South.

\section{Student Sexual Violence on Transit}

Sexual harassment and other forms of sexual violence in public spaces are everyday occurrences for women and girls around the world. This lack of safety impacts many women's ability to participate with no worry in school, work and public life activities (UN, 2017). Scholars have shown that lack of perceived safety is more prevalent among women than men (Ceccato \& Paz, 2017; Loukaitou-Sideris, 2009, 2012; Smith \& Cornish, 2006; Yates \& Ceccato, 2020) and that a substantial proportion of young women who are sexually victimized are recurrent victims who experience more than one type of sexual victimization (Fisher, Daigle, \& Cullen, 2010). As suggested by Smith (2008), differences between male and female victimization patterns are important because they may help crime prevention specialists determine the types of measures that are most appropriate for preventing particular crimes.

The \#MeToo movement has brought attention to sexual violence in different arenas, focusing primarily on workplaces and universities. However, some researchers have also started examining sexual violence in public spaces and transit environments as a particular hindrance to women's mobility (Ceccato, Näsman, \& Langefors, 2020; Ceccato, Wiebe, Eshraghi, \& Vrotsou, 2017; Chowdhury \& van Wee, 2020; Loukaitou-Sideris \& Fink, 2008; Moreira \& Ceccato, 2020; Orozco-Fontalvo, Soto, Arévalo, \& Oviedo-Trespalacios, 2019). They find that in some societies, sexual violence has become normalized, and as a result, incidents are witnessed but rarely reported (Mellgren, Andersson, \& Ivert, 2018).

Transit environments are a fertile territory for sexual violence (Gekoski et al., 2015). Similar to other types of crimes, and as suggested by routine activity theory (Cohen \& Felson, 1979), sexual violence and other forms of transit crime depend on the copresence in space and time of willing offenders, suitable targets, and the absence of responsible guardians. Crowded rush hours on a bus or train car might provide the right opportunity for groping and all sorts of inappropriate and unwanted sexual behaviors (Ceccato \& Nalla, 2020; Madan \& Nalla, 2016; Nourani, Antonello, Govone, \& Ceccato, 2020). Similarly, an unguarded and desolate station during the late evening hours might just allow the anonymity that an offender needs to act (Ceccato, 2014; Hewitt \& Beauregard, 2014).

An emerging literature in cities of both the Global North and the Global South examines how sexual violence affects transit riders (e g Ceccato, 2017, Chowdhury \& van Wee, 2020, Lea, D’Silva, \& Asok, 2017, Tripathi, Borrion, \& Belur, 2017, Beller, Garelik, \& Cooper, 1980). This literature is not comparative; empirical studies survey or interview riders in one city and in one transit system (bus or train). From this literature, we know that sexual violence behaviors are quite common in transit settings, however, victimization rates vary from one study to the other (Ding, Loukaitou-Sideris, \& Agrawal, 2020). All studies find that female transit riders are disproportionately 
victimized compared to male riders. For example, a 2007 survey of subway riders in New York city found that $63 \%$ of them had experienced harassment on the system, while $44 \%$ had witnessed a harassment incident; for the great majority (77\%) of witnessed incidents, the victims were women (Stringer, 2007). In a literature review of studies examining sexual violence on transit, Gekoski et al. (2015) found that younger women were more likely to be sexually harassed in transit environments than older women. There is very little literature on the impact of gender non-conformity or sexual orientation on sexual violence on transit. In a small study that interviewed 25 transgender and gender nonconforming transit riders, Lubitow, Carathers, Kelly, and Abelson (2017) found that they were frequently harassed while using the transit system.

Little is known about the types of harassment committed against college students in transit environments, even though it is likely that college students are disproportionately affected by sexual violence. For one, the vast majority of university students are between 18 and 29, an age group that is affected more than other age groups from sexual violence and assault (Beller et al., 1980; Tripathi et al., 2017). Second, many students are also transit-dependent; they often do not own a car and have to rely entirely on buses or trains. As an example, in Los Angeles where household automobile ownership is extremely high (about 90\%) (Governing, 2017), only 17\% of the students surveyed had access to a private car. Some universities are also located in inner city areas, and students can primarily reach them by public transportation. This means that they may be more exposed to sexual victimization than the rest of the adult population, and their mobility may be impaired because of their fear of such victimization. Lastly, some students take night classes or stay in the library until late at night to finish their work, exposing them to the risk of night travel on buses and subways.

A number of studies examine sexual violence among college students, but they focus primarily on student victimization on campuses by other students or faculty members (e g Pinchevsky et al., 2019, Hill \& Silva, 2005, Fisher, Daigle, Cullen, \& Turner, 2003, Fisher et al., 2010, Daigle, Fisher, \& Stewart, 2009). A small but recent survey of 140 female students in a New York City campus, however, found that most of them had experienced sexual victimization (from simple catcalling and whistling to sexual assault and rape) during different parts of their subway commute to and from their university (Natarajan, Schmuhl, Sudula, \& Mandala, 2017). Therefore, our study sought to expand knowledge on the topic of sexual violence in transit settings as experienced by college students, by employing larger samples of students and studying the issue comparatively.

In the following section, we give a brief overview of our findings, which are being discussed in significant detail in Ceccato and Loukaitou-Sideris (2020). We then focus primarily on the study's research design and discuss the challenges and opportunities of carrying out comparative research.

\section{Research Design: Data and Methods}

By distributing an identical survey to university students around the world, we aimed to examine the nature, type, settings, and extent of their victimization on public transport, by gender and sexual orientation, in the different city/country contexts; assess their safety needs, and examine innovative policies that can respond to these needs. 
The survey was composed of 45 questions translated into the local language of each city/country. It addressed the following questions: How prominent is the incidence of sexual violence on the bus, on the train, at the transit stop, and on the way to/from the stop or station? What types of sexual violence do college students primarily encounter in transit settings, and where and when do they mostly occur? How is the incidence of sexual violence affected by gender and sexual orientation? How do victims respond to harassment? What is the role of bystanders? How common is the reporting of such crimes? Are victimization and perceived safety affected by the types of environments students encounter while in transit, and if so, how? Where and when are most individuals afraid of being victimized? How is harassment and transit crime similar or different in different cities and cultural contexts? Lastly, how can cities and their transit operators respond to harassment and other transit crime and make transit travel safer?

For comparison purposes, we wished to have a variety of cities from different continents included in the study. Knowing that it would be difficult to access college students outside of our own countries, we utilized the user-list Transit Crime Research Network ${ }^{1}$ as well as our own network of contacts to identify scholars willing to translate our survey and distribute it to college students in their city. However, we compiled certain criteria that collaborating researchers had to meet:

- Collect a minimum sample of at least 300 university students per city

- Agree to use the same survey questions to allow comparability of results, with the exception of cases where the use of a particular question was not allowed in one country or by the Ethics Committee

- Agree to submit the survey for Ethics Committee approval, where such committee existed in the researcher's university ${ }^{2}$

- Follow a pre-determined time schedule

Ultimately, we selected willing researchers in 18 cities. These cities were VancouverCanada, Los Angeles-USA, San Jose-USA, and Mexico City-Mexico in North America, São Paulo-Brazil, Rio Claro-Brazil, and Bogotá-Colombia in South America, Stockholm-Sweden, Huddinge-Sweden, London-UK, Paris-France, Lisbon-Portugal, and Milan-Italy in Europe, Tokyo-Japan, Guangzhou-China, and Manila-the Philippines in Asia, Lagos-Nigeria in Africa, and Melbourne in Australia. Figure 1 shows the location of the samples.

The survey was distributed electronically in most study cases, either using a web platform (Wordpress, Google docs, Survey Monkey, etc.), email lists, or university pages with links to social media and to external electronic questionnaires. In a few cases (e.g. Rio Claro, Mexico City, and Huddinge), researchers distributed hard copies combined with an electronic version. In Melbourne and Manila, the link to the survey was also posted in social media. The result was the inclusion in the study of 18 cities in 6 continents, which resulted in 13,323 completed surveys by students in these cities.

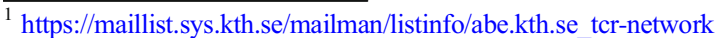

${ }^{2}$ In many countries, in particular in Europe, USA, Canada, and Australia, researchers conducting surveys with human subjects must first obtain "ethical approval" from the university and/or from a special Ethical Review Board.
} 


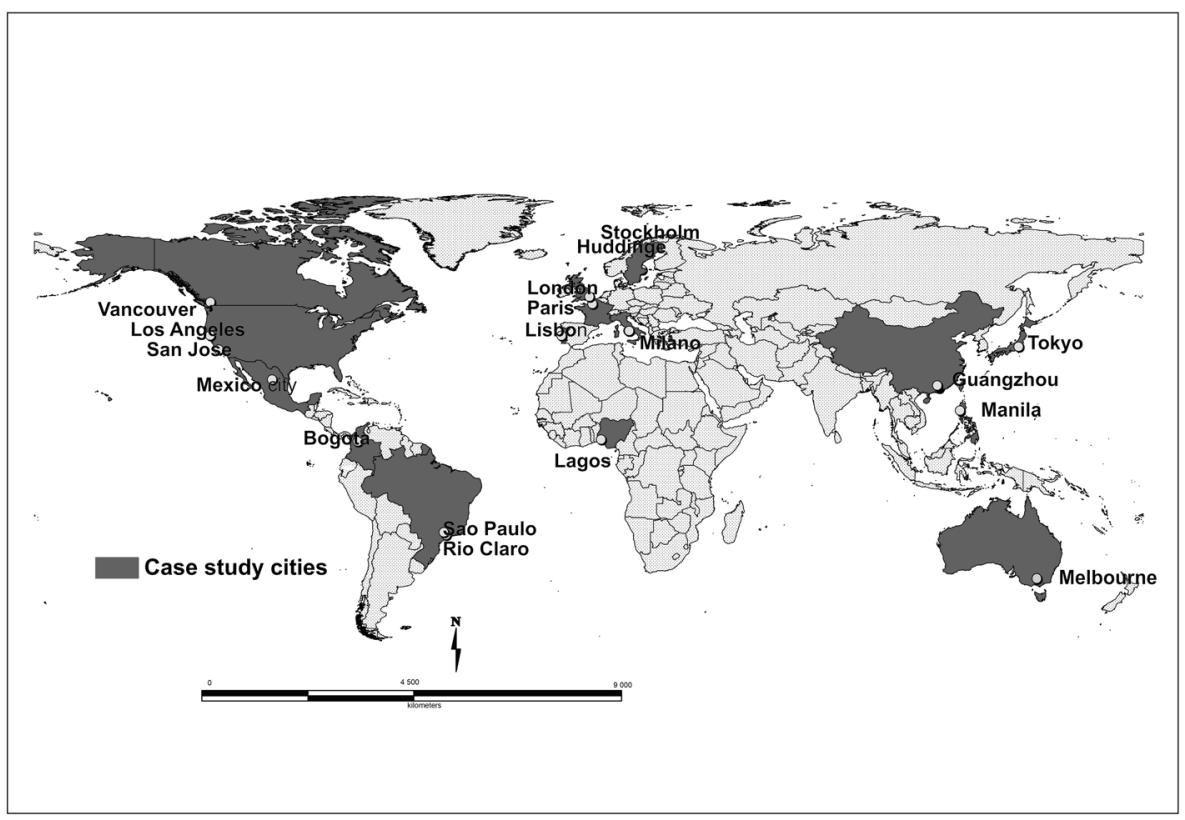

Fig. 1 Location of the 18 case study cities in the 16 continents. Source: Ceccato and Loukaitou-Sideris (2020)

Table 1 shows the samples by case study/city. Because of the different ways that the survey was distributed, the fact that it did not reach all college students in one city, and some researchers collected convenience rather than scientific random samples, we deem our study exploratory and cannot fully generalize from its findings. Nevertheless, we sought to ensure internal validity, by employing similar questions but posing them in different formulations (for example, we asked whether students had been sexually harassed over the last three years (yes/no), but also included a second closed-ended question asking students to point out from a list of 16 different sexual violence behaviors, how many they might have experienced over the last 3 years. To achieve external validity, researchers from each country discussed the relevance of the questions and reformulated them when necessary to reflect the local context, prior to distributing the final version of the questionnaire. This was identical in all countries, with the exception of one or two questions about racial/ethnic background or sexual orientation, which were absent from some cities (see later discussion). Therefore, we believe we were able to achieve some meaningful comparisons among cities, situations, settings, and students.

We should note that while most researchers were able to reach and exceed the requested minimum sample of 300 students, in two cities - Lagos and London - the researchers were only able to collect smaller samples. Overall, however, the average sample size was 650 students (ranging from a maximum sample size of 2507 students in Lisbon, to a minimum sample size of 119 students in London).

In order to create comparable datasets, we provided instructions to all researchers asking them to compile descriptive statistics from their survey data covering eight themes: 1) extent of harassment in transit settings; 2) influence of gender and sexual 
Table 1 Description of the 18 case studies by location, population and sample

\begin{tabular}{|c|c|c|c|c|c|c|c|}
\hline Continent & Country & City Name & Population & $\begin{array}{l}\text { Dominant } \\
\text { public transp. } \\
\text { Mode }\end{array}$ & $\begin{array}{l}\text { Universities } \\
\text { involved }\end{array}$ & $\begin{array}{l}\text { Sample } \\
\text { size }\end{array}$ & $\begin{array}{l}\text { Female/ } \\
\text { Male }\end{array}$ \\
\hline Asia & Japan & Tokyo & $13,857,443$ & Rail and subway & $\begin{array}{c}\text { Multiple universities } \\
\text { in Tokyo area }\end{array}$ & 400 & $196 / 196$ \\
\hline Asia & China & Guangzhou & $14,904,400$ & Subway & SCUT \& SCAU & 402 & $202 / 191$ \\
\hline Asia & The Philippines & Manila & $12,877,253$ & $\begin{array}{c}\text { Jeepney, LRT } \\
\text { and MRT }\end{array}$ & $\begin{array}{l}\text { University of } \\
\text { the Philippines }\end{array}$ & 316 & $166 / 144$ \\
\hline Oceania & Australia & Melbourne & $4,700,000$ & $\begin{array}{l}\text { Train and } \\
\text { tram, followed } \\
\text { by bus }\end{array}$ & $\begin{array}{l}\text { University of } \\
\text { Melbourne } \\
\text { (primarily) }\end{array}$ & 517 & $350 / 151$ \\
\hline Africa & Nigeria & Lagos & $20,000,000$ est. & Bus & Univ. of Lagos & 270 & $149 / 115$ \\
\hline South America & Colombia & Bogotá & $7,181,469$ & Bus & $\begin{array}{l}\text { University of } \\
\text { Los Andes }\end{array}$ & 1065 & $531 / 522$ \\
\hline \multirow[t]{2}{*}{ South America } & Brazil & São Paulo & $12,176,866$ & Bus and rail & $\begin{array}{l}\text { USP (Cidade } \\
\text { Universitária) }\end{array}$ & 557 & $371 / 179$ \\
\hline & & Rio Claro & 201,473 & Bus & UNESP & 462 & $215 / 197$ \\
\hline \multirow[t]{2}{*}{ North America } & USA & Los Angeles & $3,792,621$ & Bus, Metro & UCLA & 448 & $278 / 150$ \\
\hline & & San Jose & $1,046,079$ & Bus and rail & $\begin{array}{c}\text { San Jose State } \\
\text { University }\end{array}$ & 891 & $437 / 403$ \\
\hline North America & Canada & Vancouver & 631,486 & SkyTrain \& Bus & $\begin{array}{l}\text { Simon Fraser } \\
\text { University }\end{array}$ & 304 & $235 / 57$ \\
\hline Central America & Mexico & Mexico City & $8,855,000$ & Bus & CU Nezahualcóyotl & 383 & $191 / 188$ \\
\hline \multirow[t]{2}{*}{ Europe } & Sweden & Stockholm & 965,232 & $\begin{array}{l}\text { Bus and rail, } \\
\text { metro/train }\end{array}$ & $\mathrm{KTH}$ & 1122 & $478 / 583$ \\
\hline & & Huddinge & 112,000 & Bus and rail & Södertörn University & 309 & $230 / 64$ \\
\hline Europe & Portugal & Lisbon & 547,773 & Rail and bus & $\begin{array}{l}\text { Multiple in } \\
\text { Lisbon area }\end{array}$ & 2507 & $1815 / 640$ \\
\hline Europe & UK & London & $8,170,000$ & $\begin{array}{l}\text { Bus and } \\
\text { Underground }\end{array}$ & $\begin{array}{l}\text { Multiple in } \\
\text { London area }\end{array}$ & 119 & $69 / 47$ \\
\hline Europe & France & Paris & $2,140,526$ & Rail & SciencesPo & 740 & $574 / 156$ \\
\hline Europe & Italy & Milan & $1,400,000$ & Rail & $\begin{array}{l}\text { Università } \\
\text { Cattolica del } \\
\text { Sacro Cuore - } \\
\text { Milan Campus }\end{array}$ & 898 & $637 / 162$ \\
\hline
\end{tabular}

orientation on harassment; 3) perceptions of safety in three different types of transit environments (transit vehicle, transit stops, route to/from the stop); 4) extent of precautions taken by students when traveling by transit; 5) influence of spatial and temporal characteristics of the setting on sexual violence; 6) extent of reporting of sexual violence incidents; 7) respondents' suggestions for safer transit environments; and 8) recommendations for responding to sexual violence on transit.

We asked that all researchers analyze their survey data by gender separately, and also by transit mode (bus or rail) and transit setting (transit vehicle, transit stop, trip to/ from stop). For those who were able to gather information about sexual orientation, we also requested that they examine how sexual orientation affected levels of victimization. We compared the samples with each other using spreadsheets and standard statistical software. The final analysis focused on the identification of commonalities and differences among the case studies and the possible reasons for those patterns. We 
collected information for this comparative analysis from all the researchers by asking them to respond to a specific set of questions. The major findings from this comparative framework are discussed in the next section.

Researchers were later invited to write a 2500 -word essay discussing contextual facts about their city and their survey findings. Ten researchers were able to meet in Stockholm in October 2018, where they presented these preliminary results. During this meeting, the structure of the analysis was further discussed and researchers were split into groups to work on four cross-cutting themes:1) the influence of sociodemographic/intersectional characteristics on sexual violence; 2) the influence of the environmental characteristics of the setting on sexual violence; 3 ) the (under)reporting of sexual violence incidents; and 4) precautions taken by transit riders to avoid harassment. These topics were chosen because they are theoretically relevant to the understanding of transit crime and sexual violence and have implications for practice.

\section{Results: Students' Sexual Violence on Transit, Safety Perceptions and Impacts on Mobility}

In this section we give a brief summary of the survey findings, which can be found in great detail in Ceccato and Loukaitou-Sideris (2020). Responses from the 13,323 students in the 18 cities showed that the extent of harassment ranges considerably from one city to the other, by transport mode, by different stages of the trip, by time of the day, and by different groups of individuals - but in all cities, female students were by far more sexually harassed than male students. Verbal sexual violence is more common, followed by physical sexual violence, and nonverbal sexual violence.

The range of victimization varied highly among the city samples, ranging from $14 \%$ of female respondents in Tokyo to $92 \%$ of female respondents in Mexico City. Researchers were allowed to ask about sexual orientation only in 13 cities; in eight of these cities, LGBTQI students were victimized at somewhat higher rates than straight students. The bus system attracted more incidents of harassment than the train system in some cities, but the opposite was true for other cities. Thus for example, students in Stockholm and Tokyo indicated that more harassment incidents occurred on the train than on the bus, while the opposite was true in São Paulo and Los Angeles. On the other hand, we found that different types of harassment were more prominent at different spatial settings. Groping was the most prominent mode of physical harassment in all cities, and it tended to happen on the transit vehicle. On the other hand, students were more likely to receive sexual comments while waiting at the transit stop, or become victims of stalking while walking to or from the stop. The elements of the physical and social environment of the transit setting that students tended to indicate as problematic and even encouraging harassment events (such as darkness, isolation, poorly guarded setting, presence of intoxicated individuals and panhandlers) were characteristically similar from city to city (for more details, see Ceccato and Loukaitou-Sideris (2020).

Although sexual violence against university students in transit environments is unfortunately a common occurrence globally, researchers found significant levels of underreporting of the harassment incidents in all cities. The survey asked students who indicated they had been victimized, if they had reported the incident to the police, transport operator or bus driver, friends, or family. In all cities, those 
who chose to report the incident mostly reported it only to family or friends. Underreporting was widespread. The median level of reporting to any entity was $22 \%$ of the incidents and ranged from a low $8 \%$ of the incidents (in Rio Claro, Mexico City, and Los Angeles) to a high $68 \%$ of the incidents in Guangzhou. Additionally, students reported that in most cases, bystanders witnessing a harassment incident failed to intervene in a way that would be helpful for its prevention: speaking to the victim or offender, or trying to intervene or assist in some other way (Ceccato and Loukaitou-Sideris 2020). Figure 2 illustrates the percentage of women's victimization from sexual violence in rail-bound systems and the percentage of incident reporting.

Female students in all cities felt more unsafe in transit settings than their male counterparts (Fig. 3b), especially during the nighttime. However, we found significant differences in the perceptions of safety (or lack thereof) among students in different cities, which correspond to the differences in the victimization rates (compare Fig. 3a and b). Thus, while only $1 \%$ of female students and $7 \%$ of male students in Mexico City indicated feeling always or often safe in the bus system after dark, $67 \%$ of female students and $88 \%$ of male students in Stockholm felt safe in the buses and bus stops of their city after dark.

This lack of perceived safety affects women's mobility. In all cities, female students took many more precautions than male students when present in transit environments. However, and as Fig. $3 \mathrm{c}$ illustrates, the percentage of students taking precautions varied considerably from city to city. Dressing only in a certain way to avoid sexual violence was a very common strategy among many women students. In some cities, such as for example in Tokyo and Guangzhou, more than half of the women riders indicated following this strategy, while in Los Angeles one fifth of the students indicated carrying

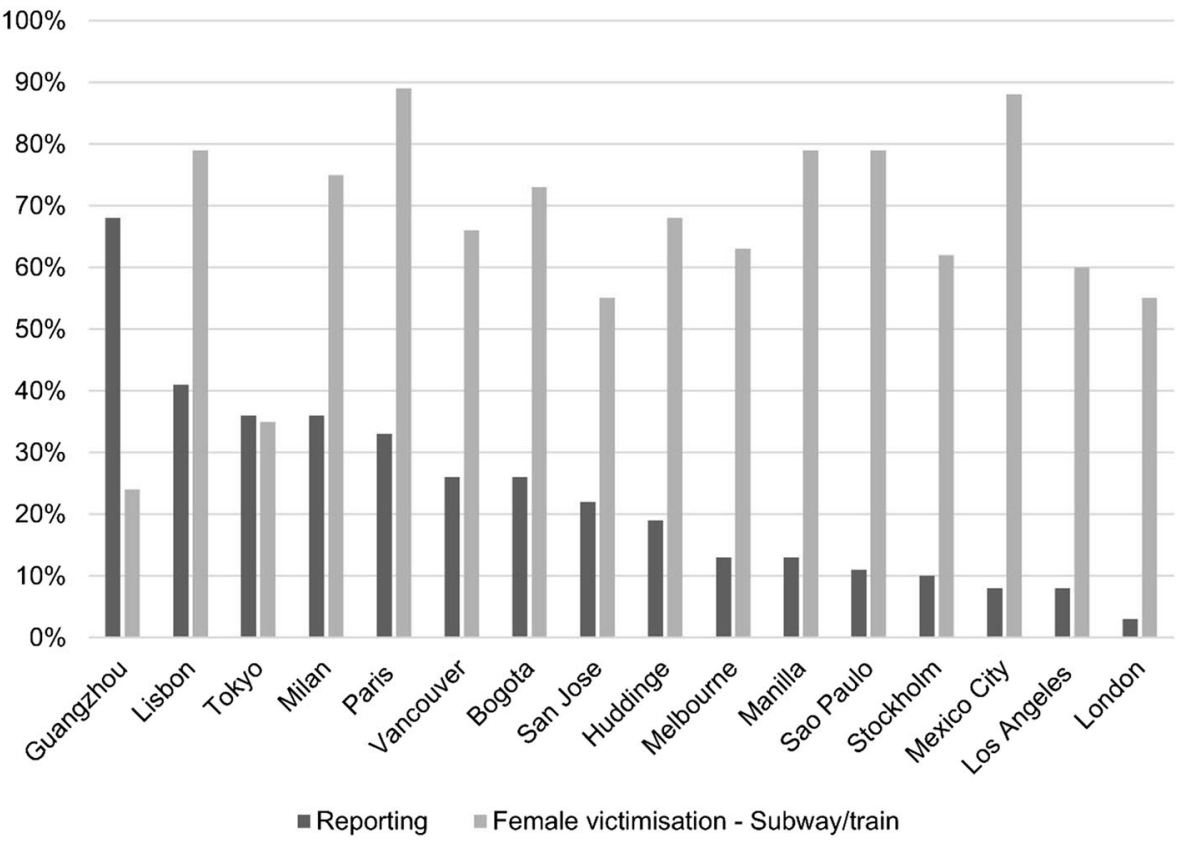

Fig. 2 Percentages of female students reporting victimization from sexual violence in railway systems compared to percentages of incidents reported. Note that the sample of students from London was relatively smaller than those from other universities, $N=119$ 


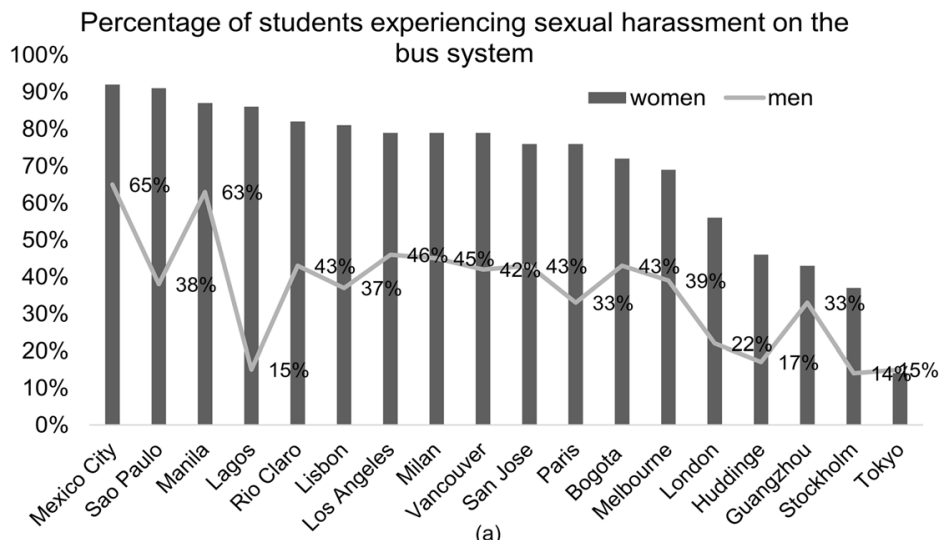

(a)

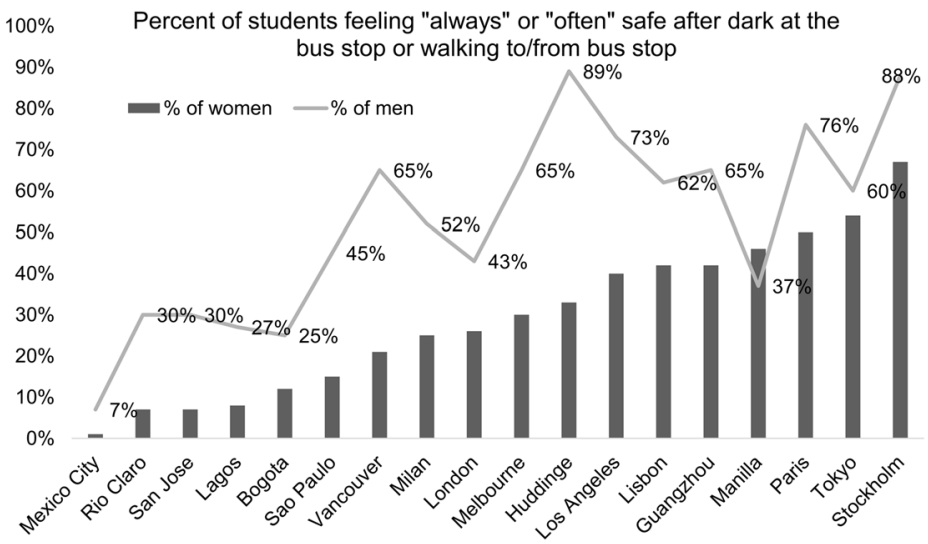

(b)

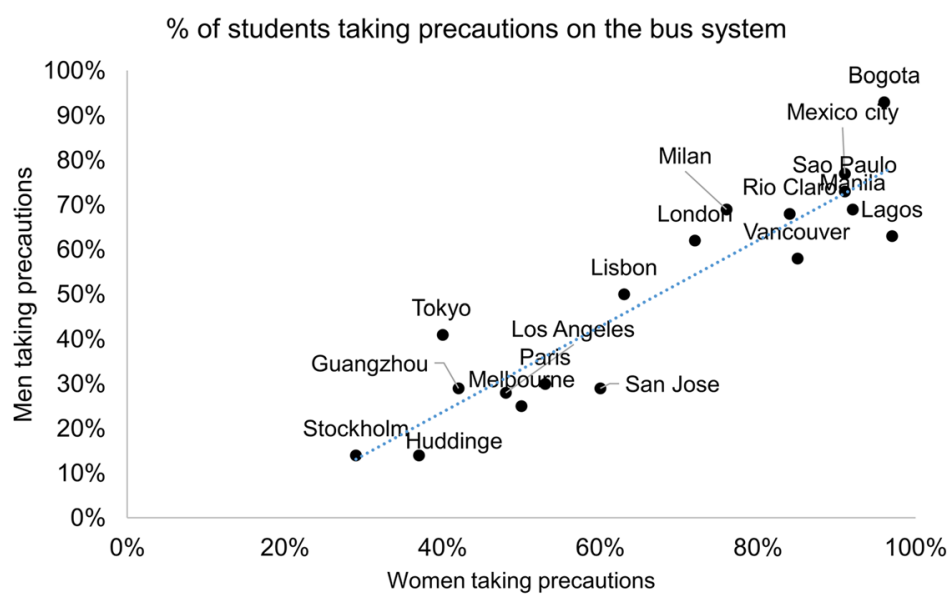

(c)

Fig. 3 a Percent of female and male students experiencing harassment on the bus system in 18 cities, b Percent of students feeling "always" or "often" safe after dark on the bus in 18 cities, c Percent of students taking precautions on the bus system in 18 cities. Source: Authors. Note that the samples of students from London and Lagos were relatively smaller than those from other universities 
some kind of weapon (not necessarily a gun but often pepper spray, keys or another sharp object) as a precaution. Female students in European cities commonly avoided travelling by transit during nighttime, or avoided certain bus stops and transit routes, which had clear impacts on their daily mobility patterns (Ceccato and LoukaitouSideris 2020).

\section{Discussion: Challenges and Opportunities of Comparative Research}

In this section, we discuss the challenges related to ethical, cultural and translational aspects of the comparative study encountered by the researchers, as well as the opportunities provided by this study.

\section{Challenges}

One of the challenges that comparative studies such as ours encounter relates to different standards and timeframes required for obtaining approval for surveys involving human subjects from relevant university authorities and/or designated Ethical Review Boards. We found that this process varied from one country to the other. Some countries did not have mandatory reviews, while others required reviews but with varying standards based on different cultural norms, and even different national policies. Overall, this process turned out to be longer than anticipated, taking from one to four months, depending on the country.

These differences in cultural norms made it impossible to standardize all survey questions. For example, in some cities, such as those in the US, we had no problem asking the question about a respondent's race/ethnicity. But in Sweden, this question had to be substituted with a question about a respondent's "country of birth/origin." In some cities, the race/ethnicity or ethnic origin question had to be omitted completely, because the law does not allow asking questions about race, ethnicity or religious beliefs. Similarly, in some cities, such as for example Paris, it is not considered appropriate to ask about someone's sexual orientation in surveys, and this question had to be omitted by researchers in five cities. It took a number of months and multiple emails until we could agree upon a minimum set of questions that were the same for everyone.

In order to make comparisons with other cities possible, questions were later translated from English into six additional languages (Portuguese, Spanish, French, Italian, Japanese and Chinese) using sharable spreadsheets over the internet. This sharing platform worked well and greatly simplified the process of comparison. But even within the same language (English) different countries may use different terms for the same concept. For example, public transit, mass transit or rapid transit systems, are terms most often used in the US, while in the UK public transport was a more common term. Some English-speaking countries use the term "college students," others use "university students," and yet others "tertiary students." These language variations make imperative the use of native speakers/translators in each country.

Researchers studying the topic of sexual violence should define carefully the term for survey respondents. In our analysis, we noticed that the way the question about harassment victimization was formulated influenced responses. For example, one 
question asked if the student had experienced sexual violence in transit environments, without defining the term. A later question in the survey asked students to indicate if they had experienced while using the transit system any one of 16 listed harassment behaviors. In all cities, fewer students responded positively to the first question than the number of students who indicated that they had been exposed to at least one harassment behavior. Studies have shown that the accuracy of the measurement of sexual violence - in particularly rape - in survey research can be influenced by the wording of the survey; they recommend the use of behaviorally specific questions because "they use words and phrases that describe to the respondent exactly what behavior is being measured" (Fisher, 2009: 143). Since the definition of sexual violence and harassment may vary among respondents and even among countries, the researcher's definition should be stated clearly. An additional interpretation of our finding is that there is also possibly a 'normalization' of sexual harassment in transit environments, namely certain sexual behaviors (such as for example calling someone 'babe' or 'honey') may be so omnipresent that are considered normal by some respondents and do not constitute harassment in their minds. These perceptions are likely different in different country/ city contexts, therefore definition and clarification of terms used in a comparative study are very important.

In all but two cases, our researcher collaborators were able to gather the minimum requested sample size of 300 students and some researchers were able to obtain significantly higher samples. To do so, they often had to follow different strategies such as adding an additional university, having a raffle with small rewards of "lucky money," or advertising survey links through social media and, in the case of Lisbon, through the city's web portal. But this variety of outreach also meant that many researchers used convenience samples and not scientific random samples. In addition, many researchers had difficulty achieving a gender-balanced sample and were ultimately unable to do so, because they found female students much more eager to respond to a survey about sexual violence than their male colleagues. While most researchers sent the survey to all students in their university, one researcher targeted students in courses with a more male profile (such as Engineering), while another researcher oversampled more male than female students. Such interventions could help achieve a more gender-balanced sample and should be considered in future studies.

The coordination of so many researchers with different schedules and living in different time zones proved at times challenging. Digital communication platforms such as Skype or Zoom now make international collaborations easier. But it is almost impossible to simultaneously "meet" over the internet with multiple researchers residing in multiple time zones. For this reason, during the process of data analysis, and especially for analyzing the data on the cross-cutting themes, we had to split researchers into smaller groups and arrange for a division of labor. Ultimately, we were able to put together a schedule of tasks to accommodate time differences between Manila, Stockholm, Bogotá, and Los Angeles!

In order to homogenize the analysis, we created an analytical framework and shared it via email with all the researchers. We set a schedule for the completion of each methodological step (e.g. survey data collection, spreadsheet with results, descriptive statistics, regression modeling, final write-up) and planned deliverables for each step. After we agreed upon the types of analysis for each question, it was time to compare results. But comparing and analyzing the responses from 13,323 students who each 
completed a 45-question survey is a voluminous task, and we had to often double- and triple-check the responses that we were receiving; in some instances we chose to eliminate responses from comparisons because the findings were not robust due to small subsamples (for instance, in a few case study cities samples from particular ethnic/racial groups or LGBTQI individuals were particularly small). This was an extremely time-demanding task as it required multiple communications with those involved in the project. We combined statistics, compared results, checked numbers, and re-run regression models. During that time, we sent hundreds of emails, back and forth, before finally agreeing on a framework that could be used to report the comparative findings.

Because convenience sampling was often employed, and also because the samples in some cities were rather small, we were aware from the beginning that our findings would be exploratory, and only general conclusions could be drawn from these samples. The commonality among the samples was the age and status of respondents - all samples were composed of young adults, who were college students in different cities around the world. In practice, this means that our findings are not applicable to the general population even within the same city and country contexts. Responding students were from different majors, living in different cities (most in the Global North, but also some in the Global South), with different public transportation infrastructures (from the auto-dominated Los Angeles to the subway-centric Tokyo), and with different population sizes. While the relatively large cumulative samples of students allowed for a robust statistical analysis across genders, the typically small sub-samples of LGBTQI students or students of different ethnic/race backgrounds in each city prevented a robust statistical analysis of victimization patterns among different subgroups.

\section{Opportunities}

The opportunities that this comparative research provided, however, far outweighed the challenges. For one, we were able to study a phenomenon with the evidence of largescale, comparative data. With the exception of a couple of studies by NGOs that have tried to examine sexual violence against women in transit in more than one city or country (Allen, Cardenas, Pereyra, \& Sagaris, 2018), and literature reviews that synthesize the findings of different studies (Gekoski et al., 2015; Ding et al., 2020), scholarly empirical comparative work on the topic is missing.

The study gave us the opportunity to establish, with the backing of empirical data, that sexual violence on transit is a global phenomenon; it is more prevalent in some regions (e.g. South and Central America) than others (e.g. Southeast Asia). Gender (being female) and, in some countries, sexual orientation (being LGBTQI) heighten the likelihood of harassment victimization. Some elements of the physical and social environment, which tend to be similar in most cities, tend to aggravate the risk of harassment. Even in the era of the \#Me Too movement, sexual violence in transit settings is significantly underreported, and leads many female students to adopt precautionary measures when traveling, at times affecting their mobility and travel choices. Lastly, the comparative perspective also allowed us to identify contextual and cultural nuances among cities, such as for example the significant differences in reporting rates in China compared to other countries. 
But arguably the most significant opportunity that this study provided was the comparison of proposed measures to tackle harassment. Sexual violence is a global phenomenon, but how, where, and to what extent it happens may be context specific. Therefore, responses may need to be tailored to better tackle the problem, as "one-size fix all" initiatives to sexual violence may be ineffective. At the same time, the exchange of ideas and experience from different contexts can be informative, and some responses may be quite effective in more than one contexts. We turn to this topic next.

\section{Tackling Sexual Violence in Transit Environments: Research and Practice}

Some would argue that tackling sexual violence requires the change of societal norms that impose unequal conditions for women in society. While we agree with this sentiment, our focus in this study is on more immediate research and policy changes that can help alter the criminogenic conditions of places and reduce opportunities for sexual violence.

We asked our research collaborators in each city to draw from student survey responses and indicate the measures that in their view would help tackle harassment. We have separated these suggestions in two groups: 1) those that ask for more research and knowledge on harassment incidents (Table 2); and 2) those that suggest design and/ or policy interventions (Table 3).

\section{Research-Based Recommendations}

In all cities, researchers recognized that is essential to know more about the local crime dynamics, in particular where and when different sexual violence behaviors take place, in order to improve transit safety. The importance of knowing more about the effects on harassment of the quality and management of the physical and social environment was emphasized by researchers in 14 cities; a number of researchers emphasized the need to have better knowledge about the effectiveness of technological solutions, such as CCTV cameras, body worn cameras, real time timetables, apps, or drones. Taking into account the different safety needs of different groups of travelers was the third most common response, and was pointed out by more than half of the researchers in the study. Almost a similar number of researchers indicated the need for data collection about the whole journey (safety from door-to-door), and in particular, 'the last-mile' which seems to be crucial for the safety of women using public transportation. As it currently happens, most transit agencies collect transit safety data only for on the vehicle safety. However, 'the whole journey approach' to safety is fundamental in the context of the United Nation's 2030 Agenda and its goals for sustainable development. Only when we focus on safety patterns over time and space, will we be able to achieve safe travel from door to door. The study in the 18 cities showed that women riders often feel safer onboard the transit vehicle or at the station platform (even though these are settings where overcrowding significantly facilitates groping), and less safe on 


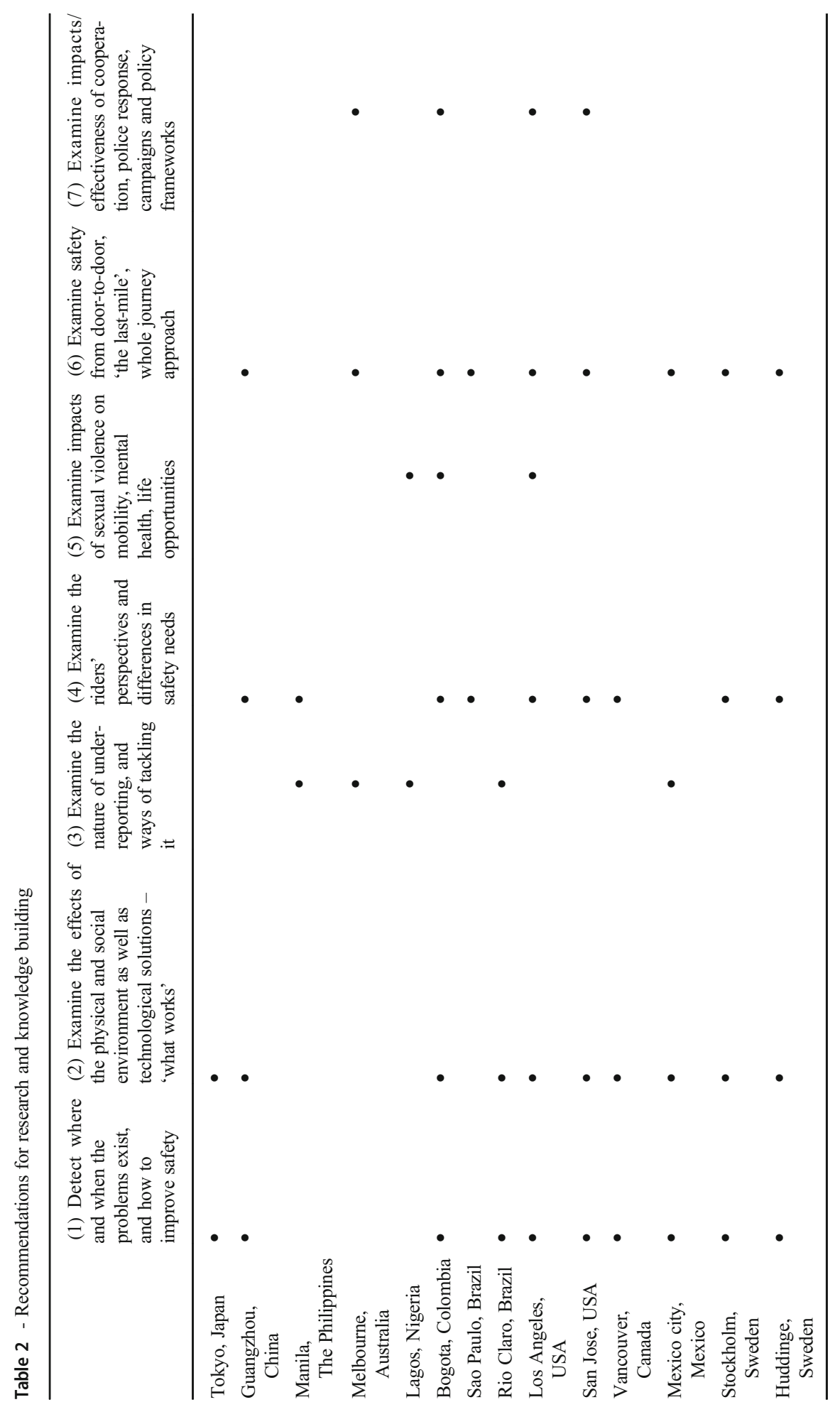




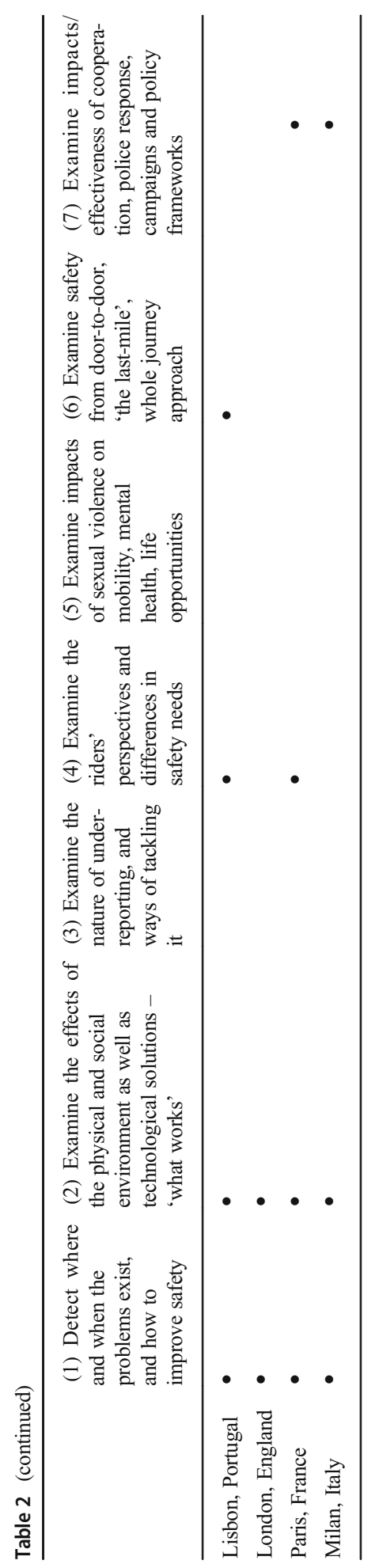




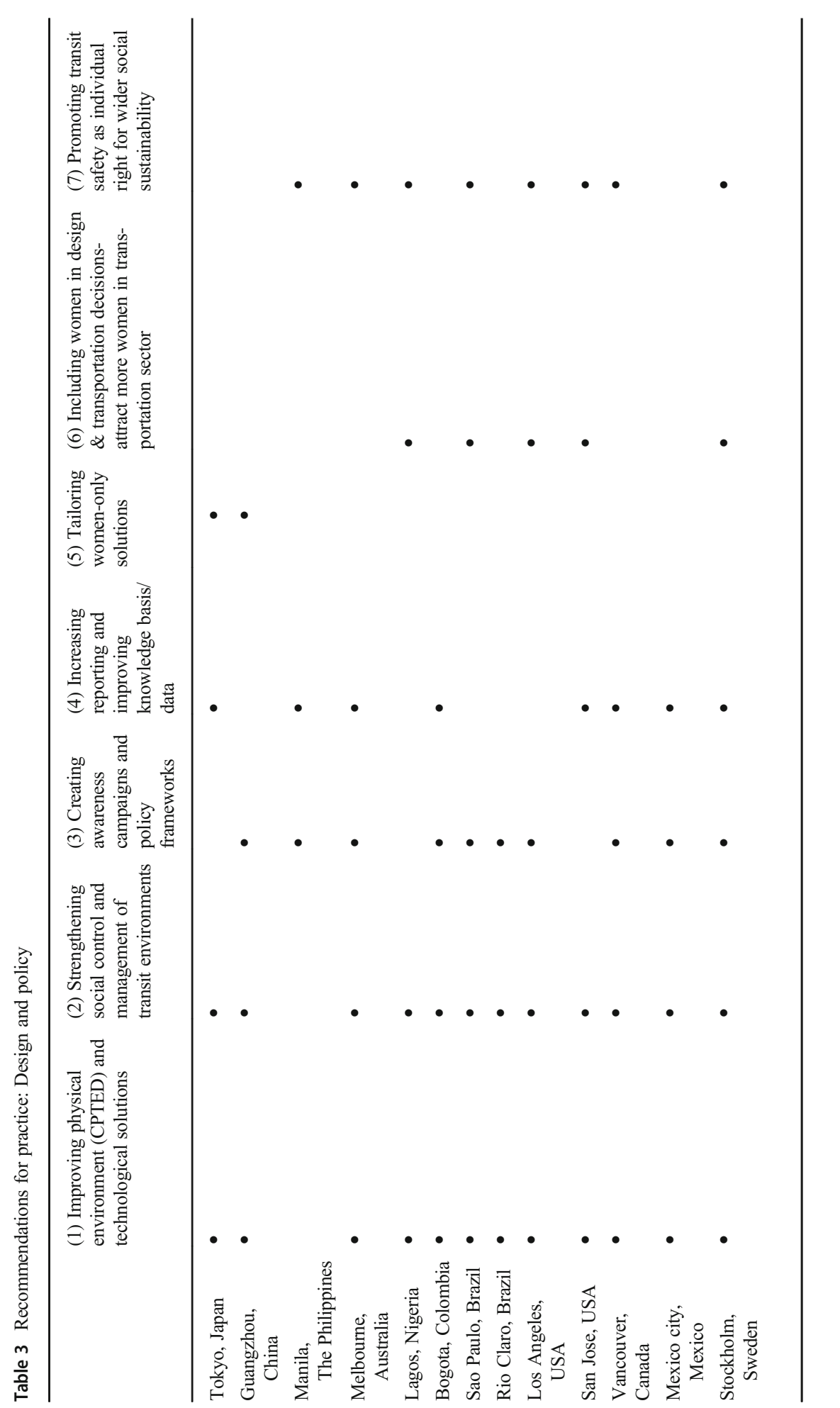




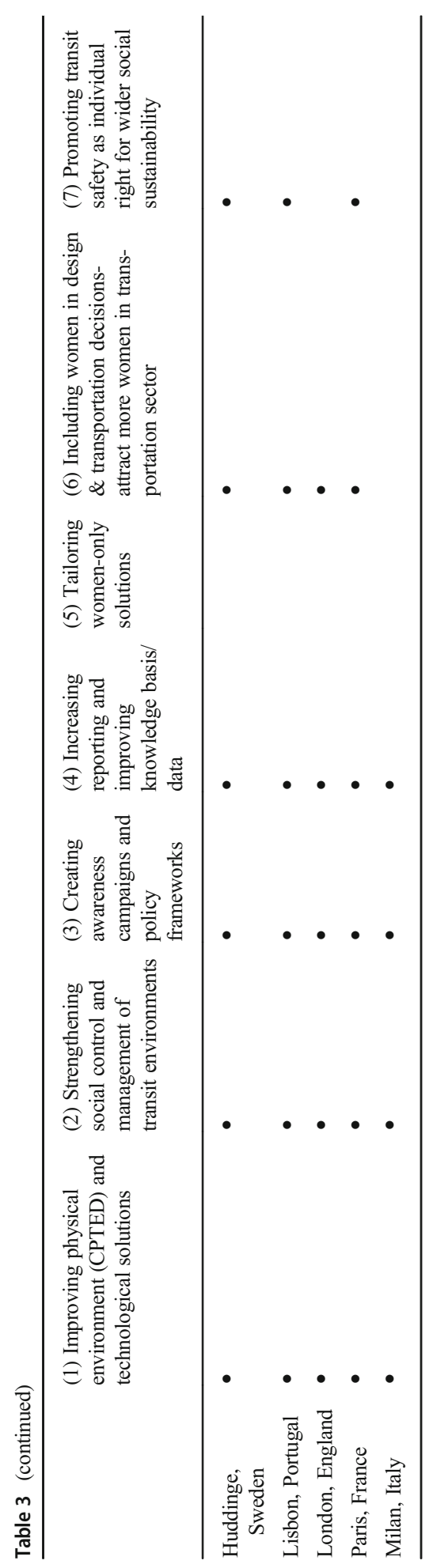


the way to the train station or waiting at the public environment of the bus stop (Ceccato and Loukaitou-Sideris 2020).

Other relevant topics that need further research and data according to the researchers include the nature of underreporting by victims and bystanders, investigating ways to tackle it, assessing what works and what does not in term of collaborative frameworks between the police, transport operators and other actors. This may also involve evaluation of effectiveness of campaigns to curb transit crime and sexual violence in transit environments. A small number of respondents noted that future research should also evaluate the impact of sexual violence on mobility, mental health, and life opportunities.

\section{Design and Policy Recommendations}

A second set of recommendations involved design and policy interventions to tackle unwanted sexual behavior and sexual crime in transit environments. Table 2 shows these recommendations grouped around 6 themes. Almost all researchers (17) noted that safety in transit environments related to changes and improvements in the physical environment of transit settings as well as the implementation of technological solutions. These would mean better lighting at platforms and bus stops, as well as at a station's surrounding areas and parking lots (for better lit first/last mile connections). Such improvements require strong cooperation among those who own or manage the station, the transport operators, and the municipalities responsible for the safety of streets leading to transport nodes.

The same number of researchers (17) called for strengthening social control and management in transit environments. A third popular suggestion included the need of creating awareness of sexual violence through educational campaigns and/or policy frameworks, by improving cooperation between police, transit operators, and researchers, and by using actions guided by evidence-based policing to guide and evaluate practices (see also the Daigle et al. (2009) for a discussion about effectiveness of college-based programs in reducing sexual victimization and its perpetration).

Eleven respondents indicated the need of viewing issues of transit safety as part of a wider agenda of city planning and social sustainability in cities. Half of the respondents (9) suggested including more women in decisions about the design of transportation environments. Some noted that this can happen if more women are recruited in the transportation sector, which in many countries is dominated by male professionals. Much less popular were recommendations about 'women-only' solutions, such as women-only trains or buses. While 'women-only' solutions may be appropriate for particular country/cultural contexts, 'they remain problematic in that they perpetuate differences rather than comprehensively addressing the deep rooted gender biases inherent in current transport planning and policy-making' (Peters, 2017, p.35).

While the recommendations were collected and meant to reflect responses for each specific city/country context, the comparative perspective allowed us to see where these recommendations converged or diverged. Thus, 'better knowledge about the effects of the physical and social environment on transit safety' was suggested by nearly all researchers, while 'better understanding of the nature of (sexual violence) underreporting' was recommended by just a few despite the fact that underreporting seemed to be quite universal. Similarly, the suggestion for "improvement of social 
control in transit environment' was almost universally proposed, while 'establishing women-only transportation modes" was recommended by only researchers in Tokyo (where it happens) and Guangzhou.

\section{Conclusions}

In a project of such global scope, there will always be incongruences and challenges when collecting and analyzing the data. This study was no exception. As discussed, important challenges included inconsistencies in the ways survey respondents were recruited, difficulty of ensuring the minimum sample size for all samples, difficulty of having gender-balanced samples, inability to include questions about race/ethnicity and sexual orientation in the surveys of some cities, and small sub-samples for certain groups, such as LGBTQI. On the other hand, our experience of coordinating this research effort via emails and digital communication platforms shows that it is possible to carry out global, comparative studies without major resources apart from a computer and an internet connection. However, two prerequisite items are important: identical research tools agreed upon and shared by all collaborators and research partners who can ensure that steps are followed timely, ethically, and with good care for quality of data and the research process.

The survey showed, without any doubt, that sexual violence/harassment in transit environments is unfortunately a common occurrence globally. However, the extent of harassment ranges considerably from one city to the other. Additionally, the omnipresence of the potential for harassment in transit settings leads to the adoption of certain behaviors, especially by female transit riders. Avoidance strategies prompt these riders to avoid particular times, travel routes, and settings that are deemed as risky, or even avoid using transit completely, opting for other transportation options. This, of course, demands changes in the way transit systems are built, but also more structural changes in society's values and attitudes towards mobility, gender equality, and safety.

Women should not have to change their daily lives and perform a lot of the "safety work" themselves (Vera-Gray, 2018), such as taking precautionary measures in order to move freely around their cities. This should be rather the responsibility of the police, transit authorities, and in the case of university students, their universities. Indeed, colleges and universities should emphasize a gendered response to sexual violence: encouraging women and bystanders to report it and empowering them to recognize that sexual offenses against them are serious infringements on their right to move freely, wherever and whenever they wish. Equally important is to consider that women are not a homogenous group. The intersections of vulnerabilities that women may find themselves in (relating to age, race/ethnicity, class, sexual orientation, or disability) have to be taken into account when designing mobility and safety policies that can no longer afford to be gender-neutral.

Acknowledgements We are grateful to our international collaborators, who despite being unfunded in many countries, managed to deliver high quality data with clear relevance for practice, and in a short timeframe. We are also very appreciative of the more than 13,000 students spread in 18 countries around the world, who participated in our survey. During the process of data acquisition, the support of our university administration and technical personnel was fundamental to access these students via email and to run the survey on university servers. 
Funding Open access funding provided by KTH Royal Institute of Technology, Department of Urban Planning and Environment.

Open Access This article is licensed under a Creative Commons Attribution 4.0 International License, which permits use, sharing, adaptation, distribution and reproduction in any medium or format, as long as you give appropriate credit to the original author(s) and the source, provide a link to the Creative Commons licence, and indicate if changes were made. The images or other third party material in this article are included in the article's Creative Commons licence, unless indicated otherwise in a credit line to the material. If material is not included in the article's Creative Commons licence and your intended use is not permitted by statutory regulation or exceeds the permitted use, you will need to obtain permission directly from the copyright holder. To view a copy of this licence, visit http://creativecommons.org/licenses/by/4.0/.

\section{References}

Allen, H., Cardenas, G., Pereyra, L., \& Sagaris, L. (2018). Ella se mueve segura (ESMS) - Un estudio sobre la seguridad personal de las mujeres y el transporte público en tres ciudades de América Latina. Retrieved from Caracas: http://scioteca.caf.com/handle/123456789/1405. Accessed 22 Nov 2020.

Beller, A., Garelik, S., \& Cooper, S. (1980). Sex crimes in the Subway. Criminology, 18, 35-52.

Breiding, M.J.; Smith, S., Basile, K., Walters, M.L., Chen, J., Melissa, M.S., Merrik, T. (2014) Prevalence and Characteristics of Sexual Violence, Stalking, and Intimate Partner Violence Victimization — National Intimate Partner and Sexual Violence Survey, United States, 2011. Division of violence prevention, National Center for Injury Prevention and Control, CDC, https:/www.cdc.gov/mmwr/pdf/ss/ss6308.pdf. Accessed 22 Nov 2020.

Ceccato, V. (2014). The nature of rape places. Journal of Environmental Psychology, 40, 97-107. https://doi. org/10.1016/j.jenvp.2014.05.006.

Ceccato, V. (2017). Women's transit safety: Making connections and defining future directions in research and practice. Crime Prevention and Community Safety, 19(3), 276-287. https://doi.org/10.1057/s41300017-0032-5.

Ceccato, V., \& Loukaitou-Sideris, A. (Eds.) (2020). Transit Crime and Sexual Violence in Cities: International Evidence and Prevention. New York: Routledge.

Ceccato, V., \& Nalla, M. (2020). Crime and fear in public places: Towards safe, inclusive and sustainable cities. Abingdon: Routledge.

Ceccato, V., Näsman, P., \& Langefors, L. (2020). Sexual violence on the move: An assessment of Youth's victimization in public transportation. Women \& Criminal Justice, 1-19. https://doi.org/10.1080/ 08974454.2020.1733732.

Ceccato, V., \& Paz, Y. (2017). Crime in São Paulo's metro system: Sexual crimes against women. Crime Prevention and Community Safety, 19(3), 211-226. https://doi.org/10.1057/s41300-017-0027-2.

Ceccato, V., Wiebe, D. J., Eshraghi, B., \& Vrotsou, K. (2017). Women's Mobility and the Situational Conditions of Rape: Cases Reported to Hospitals. Journal of Interpersonal Violence, 0886260517699950. https://doi.org/10.1177/0886260517699950.

Chowdhury, S., \& van Wee, B. (2020). Examining women's perception of safety during waiting times at public transport terminals. Transport Policy, 94, 102-108. https://doi.org/10.1016/j.tranpol.2020.05.009.

Cohen, L. E., \& Felson, M. (1979). Social change and crime rate trends: A routine activity approach. American Sociological Review, 44(4), 588-608. https://doi.org/10.2307/2094589.

Daigle, L. E., Fisher, B. S., \& Stewart, M. (2009). The effectiveness of sexual victimization prevention among college students: A summary of "what works". Victims \& Offenders, 4(4), 398-404. https://doi.org/10. 1080/15564880903227529.

Ding, H., Loukaitou-Sideris, A., \& Agrawal, A. W. (2020). "Sexual harassment and assault in transit environments: A review of the English-language literature." Journal of Planning Literature, 35(3), 267-280.

Fisher, B. S. (2009). The effects of survey question wording on survey estimates: Evidence from a quasiexperimental design. Violence Against Women, 15(2), 133-147.

Fisher, B. S., Daigle, L. E., \& Cullen, F. T. (2010). What distinguishes single from recurrent sexual victims? The role of lifestyle-routine activities and first-incident characteristics. Justice Quarterly, 27(1), 102-129. https://doi.org/10.1080/07418820902763061.

Fisher, B. S., Daigle, L. E., Cullen, F. T., \& Turner, M. G. (2003). Reporting sexual victimization to the police and others: Results from a National-Level Study of college women. Criminal Justice and Behavior, 30(1), 6-38. https://doi.org/10.1177/0093854802239161. 
Gekoski, A., Gray, J. M., Horvath, M. A. H., Edwards, S., Emirali, A., \& Adler. J. R. (2015). “'What works' in reducing sexual harassment and sexual offences on public transport nationally and internationally: A rapid evidence assessment." http://eprints.mdx.ac.uk/15219/1/Gekoski\%2C\%20Gray\%2C\%20Horvath\% 2C\%20Edwards\%2C\%20Emirali\%20\%26\%20Adler\%202015.pdf. Accessed 11 Nov 2020.

Governing (2017). Vehicle Ownership in U.S. Cities: Data and Map. governing.com/gov-data/car-ownershipnumbers-of-vehicles-by-city-map.html. Accessed 22 Nov 2020.

Hewitt, A., \& Beauregard, E. (2014). Sexual crime and place: The impact of the environmental context on sexual assault outcomes. Journal of Criminal Justice, 42(5), 375-383. https://doi.org/10.1016/j.jcrimjus. 2014.05.003.

Hill, C., \& Silva, E. (2005). Drawing the line: Sexual violence on campus. Washington, DC: American Association of University Women (AAUW) Educational Foundation.

Lea, S. G., D’Silva, E., \& Asok, A. (2017). Women's strategies addressing sexual violence and assault on public buses: An analysis of crowdsourced data. Crime Prevention and Community Safety, 19(3), 227239. https://doi.org/10.1057/s41300-017-0028-1.

Loukaitou-Sideris, A. (2009). How to ease Women's fear of transportation environments: Case studies and best practices. San Jose: Mineta Transportation Institute.

Loukaitou-Sideris, A. (2012). Safe on the move: The importance of the built environment. In V. Ceccato (Ed.), The urban fabric of crime and fear (pp. 85-110). Dordrecht, Heidelberg, New York, London: Springer Netherlands.

Loukaitou-Sideris, A., \& Fink, C. (2008). Addressing Women's fear of victimization in transportation settings: A survey of U.S. transit agencies. Urban Affairs Review, 44(4), 554-587. https://doi.org/10.1177/ 1078087408322874.

Lubitow, A., Carathers, J., Kelly, M., \& Abelson, M. (2017). Transmobilities: Mobility, harassment, and violence experienced by transgender and gender nonconforming public transit riders in Portland, Oregon. Gender, Place and Culture, 24(10), 1398-1418. https://doi.org/10.1080/0966369X.2017. 1382451 .

Madan, M., \& Nalla, M. K. (2016). Sexual violence in public spaces: Examining gender differences in perceived seriousness and victimization. International Criminal Justice Review 26(2), 80-97.

Mellgren, C., Andersson, M., \& Ivert, A.-K. (2018). "It happens all the time": Women's experiences and normalization of sexual violence in public space. Women \& Criminal Justice, 28(4), 262-281. https://doi. org/10.1080/08974454.2017.1372328.

Moreira, G., \& Ceccato V. (2020). Gendered mobility and violence in the São Paulo metro, Brazil. Urban Studies. https://doi.org/10.1177/0042098019885552.

Natarajan, M., Schmuhl, M., Sudula, S., \& Mandala, M. (2017). Sexual victimization of college students in public transport environments: A whole journey approach. Crime Prevention and Community Safety, 19(3), 168-182. https://doi.org/10.1057/s41300-017-0025-4.

Nourani, F., Antonello, S. L., Govone, J. S., \& Ceccato, V. (2020). Women and LGBTI youth at target: Assessing transit safety in Rio Claro, Brazil. In M. V. Ceccato \& Nalla (Eds.), Crime and fear in public places: Towards safe, inclusive and sustainable cities (pp. 176-193). Routledge.

Orozco-Fontalvo, M., Soto, J., Arévalo, A., \& Oviedo-Trespalacios, O. (2019). Women's perceived risk of sexual violence in a bus rapid transit (BRT) system: The case of Barranquilla, Colombia. Journal of Transport \& Health, 14, 100598. https://doi.org/10.1016/j.jth.2019.100598.

Peters, D. (2017). Gender and sustainable urban mobility. Global Report on Human Settlements 2013. https:// doi.org/10.13140/RG.2.1.4746.9287.

Pinchevsky, G. M., Magnuson, A. B., Augustyn, M. B., \& Rennison, C. M. (2019). Sexual victimization and sexual violence among college students: A comparative analysis. Journal of Family Violence, 35, 603618. https://doi.org/10.1007/s10896-019-00082-y.

Smith, M. (2008). Addressing the security needs of women passengers on public transport. Security Journal, 21, 117-133. https://doi.org/10.1057/palgrave.sj.8350071.

Smith, M. J., \& Cornish, D. B. (2006). Secure and Tranquil Travel-Preventing Crime and Disorder on Public Transport (U. o. London Ed.). London: UCL Jill Dando Institute of Crime Science.

Stringer, S. M. (2007). Hidden in Plain Sight: Sexual violence and Assault in the New York City Subway System. . Retrieved from http://www.nytimes.com/packages/pdf/nyregion/city_room/20070726_ hiddeninplainsight.pdf. Accessed 22 Nov 2020.

Tripathi, K., Borrion, H., \& Belur, J. (2017). Sexual violence of students on public transport: An exploratory study in Lucknow, India. Crime Prevention and Community Safety, 19(3), 240-250. https://doi.org/10. 1057/s41300-017-0029-0.

UN (2017). Safe cities global initiatives. UN, 2. Retrieved from www.unwomen.org. Accessed 22 Nov 2020. Vera-Gray, F. V. (2018). Right amount of panic: How women trade freedom for safety. Bristol: Policy press. 
Yates, A., \& Ceccato, V. (2020). Individual and spatial dimensions of women's fear of crime: A Scandinavian study case. International Journal of Comparative and Applied Criminal Justice, 1-16. https://doi.org/10. 1080/01924036.2020.1719531.

Publisher's Note Springer Nature remains neutral with regard to jurisdictional claims in published maps and institutional affiliations.

Vania Ceccato is a Professor at the Department of Urban Planning and Environment, KTH Royal Institute of Technology, Stockholm, Sweden. Her research is international in outlook and has focused on the situational conditions of crime and fear in urban and rural environments.

Anastasia Loukaitou-Sideris is a Distinguished Professor of Urban Planning and the Associate Dean of the Luskin School of Public Affairs at UCLA. She has published ten books and over 100 research articles and book chapters.

\section{Affiliations}

\section{Vania Ceccato $^{1} \cdot$ Anastasia Loukaitou-Sideris $^{2}$}

1 School of Architecture and the Built Environment, KTH Royal Institute of Technology, Stockholm, Sweden

2 UCLA Department of Urban Planning, Luskin School of Public Affairs, University of California, Los Angeles, Los Angeles, CA, USA 